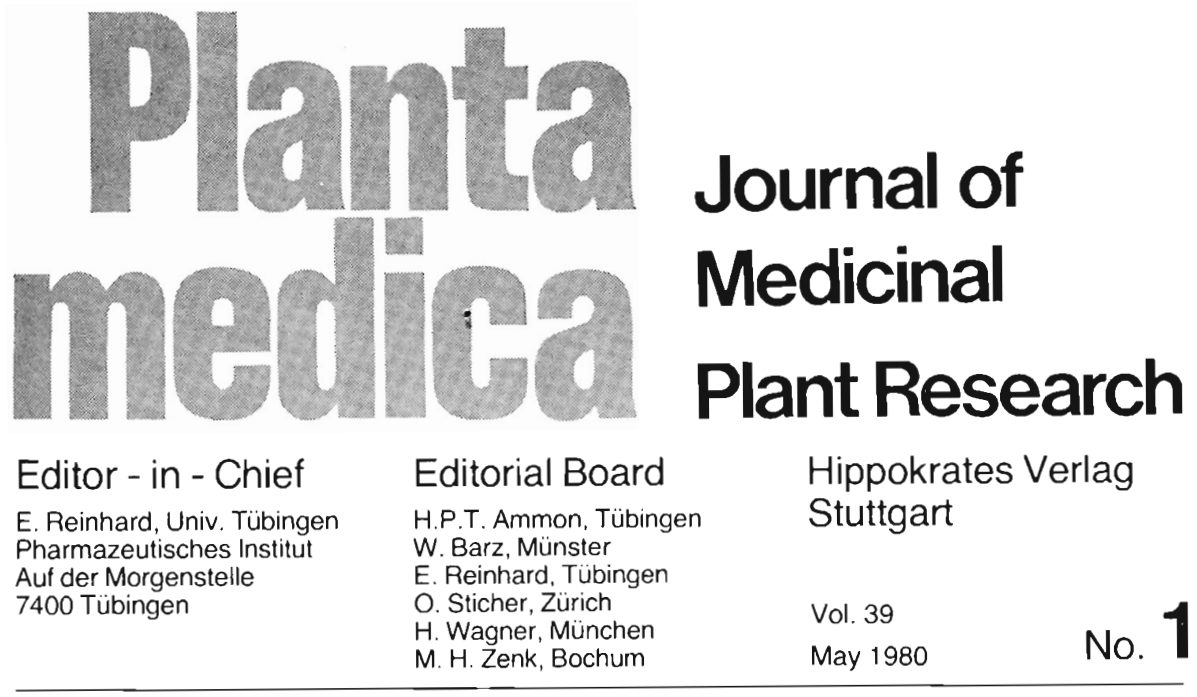

\title{
Droplet Counter-Current Chromatography and its Application to the Preparative Scale Separation of Natural Products
}

\section{Kurt Hostettmann}

Pharmazeutisches Institut der ETH, ETH-Zentrum CH-8092 Zürich, Switzerland

Key Word Index: Droplet Counter-Current Chromatography; Natural Products Isolation; Saponins; Polyphenolics; Iridoid Glycosides; Cardenolides; Alkaloids; Peptides; Lipids; Monosaccharides; Cyclitols.

\section{Abstract}

Droplet counter-current chromatography (DCCC) is a recently developed allliquid separation technique based on the partitioning of solutes between a steady stream of droplets of mobile phase and a column of surrounding stationary phase [1]. It is particularly indicated for the preparative scalc separation of polar compounds and has been applied to the isolation of various types of natural products. In many cases, the separations were achieved far more readily than by con- 
ventional chromatography and with a smaller solvent consumption. In the present paper, the principle of DCCC is described and a quick method based on thin-layer chromatography (TLC) for the selection of the solvent system is proposed. An up to date literature survey is given and the problems specific to the different classes of compounds are discussed. Advantages and limits of DCCC, as well as its position among the various available methods for the preparative scale separation, are discussed.

\section{Introduction}

The purification and the separation of relatively large amounts of compounds is often a very tedious and time-consuming operation, especially when dealing with complex mixtures such as plant extracts and other biological material.

Various chromatography methods for separating compounds in a semi-preparative and preparative scale have been developed. Column chromatography using various solid stationary phases (silica gel, alumina, polyamide, cellulose, Sephadex, etc.) is very popular and employed in most laboratories. This technique has a high capacity, but the separation time is long and the resolution power relatively low. In recent years, several preparative systems have evolved which reduce separation times to several hours. Among them, we have to mention short-column chromatography [2] and flash chromatography [3] which give very rapid separations but with moderate resolution. Preparative liquid chromatography is a more efficient method and is becoming very popular. We have been successful with this method and have applied it to the isolation of pure compounds from crude medicinal plant extracts [4]. The separation time was very short, the resolution high, but a preliminary purification of the sample prior to injection was necessary in order to avoid column contamination.

All the techniques mentioned above use a solid stationary phase or a liquid stationary phase fixed on an "inert" support. The presence of this solid packing material in a column may cause irreversible adsorption when dealing with very polar compounds or cause modification of the solute at the liquid solid interface.

In order to avoid complications arising from solid supports, various supportfree liquid-liquid partition techniques have been developed. $[5,6,7]$

When two immiscible solvents containing solutes are shaken in a separatory funnel and then separated, the solutes are partitioned between the two phases. The ratio of solute concentration in the upper phase to the lower phase is called the partition coefficient. If the partition coefficients of two compounds differ greatly, the only process needed for separation is a one-step operation called extraction. As the nature of the substances becomes more similar, the difference of their partition coefficient decreases, hence requiring multistep extraction. Cralc, [8] designed machines in which many distribution steps, up to hundreds in number, could readily be achieved by liquid-phase transfers in all the stages simultaneously. This technique, called counter-current distribution (CCD), was used with outstanding success for the purification of natural polypeptide antibiotics. [9] 
Its applications in various fields of organic chemistry and biochemistry have been reviewed by Hrckl:k [10]. CCD has a high capacity, but the resolution power is limited. In addition, the apparatus is complex, the volumes of solvents used large and the separation time relatively long.

A simple and very efficient all-liquid separation technique called droplet counter-current chromatography (DCCC) has been developed by Tinimira et al. [1].

It is less cumbersome than CCD and has a higher resolution power. DCCC is carried out by passing droplets of a mobile phase through a column of surrounding stationary liquid phase. Recently, this technique became commercially available and we are using it extensively in our laboratories for the isolation and purification of various natural products. Most of the separations could be achieved far more readily than by conventional chromatographic methods. Sample amounts from several milligrams up to grams can easily be handled and the solvent consumption is very small. At the present time, numerous laboratories are introducing this technique and applications of DCCC to various separation problems in natural products chemistry and in biochemisty have already been published. Some authors employed DCC as abbreviation for droplet counter-current chromatography. In order to avoid confusion, it is desirable to use DCCC, since DCC is the official abbreviation of dicyclohexylcarbodiimide. Furthermore, we noticed recently that dry column chromatography was also designated by DCC.

\section{Description of the Method and Choice of the Solvent System}

DCCC grew out of the observation that a light phase with low wall surface affinity formed discrete droplets that rose through the heavy phase with visible evidence of very active interfacial motion. Under ideal conditions each droplet could become a "plate" if kept more of less discrete throughout the system [5]. The method developed by Tanimura et al. [I] exploits these ideas and consists basically of $200^{\prime}$ to 600 long vertical columns (20 to 60 $\mathrm{cm}$ ) of narrow bore glass silanized tubing ( 1.5 to $2 \mathrm{~mm}$, i.d.) interconnected in series by capillary Teflon tubes. A first step consists to fill the whole system with stationary phase followed by the injection of the sample (dissolved either in light phase or in heavy phase or in a mixture of both phases) in a sample chamber. The mobile phase is than pumped through the sample chamber and inserted with the capillary tube into the bottom of the first glass column of wider bore. A steady stream of ascending droplets is formed. When a droplet reaches the top of the column, it is delivered to the bottom of the next column through the Teflon tubing, thus regenerating new droplets. Under suitable conditions, the capillary tubing allows only the mobile phase to flow. A small amount of stationary phase may also enter the Teflon tubing initially, but the effect is insignificant. As the mobile phase moves through the column, turbulence within the droplet promotes efficient partitioning of the solute between the two phases.

Depending on the separation problem, the mobile phase may be either heavier or lighter than the stationary phase. When 


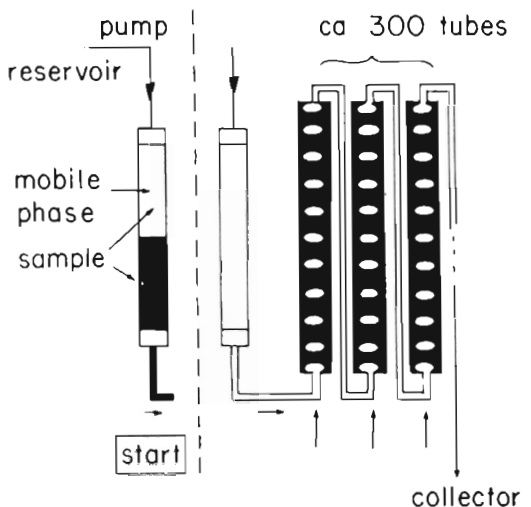

ascending mode

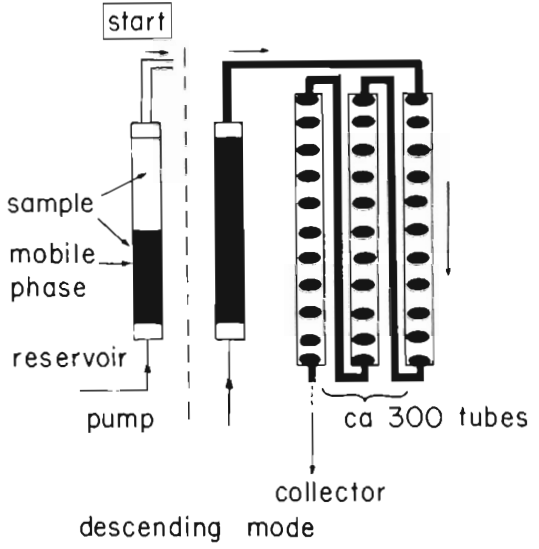

descending mode

Fig. 1. Schematic illustration of the principle of DCCC

lighter, the mobile phase is delivered at the bottom of the column (ascending mode) and, when heavier, through the top (descending mode) (Fig. 1).

Solvent systems that form two immiscible layers are usually suitable for DCCC, however there are some limitations. The generation of droplets having suitable sizes and mobility are governed by factors such as the difference in specific gravities of the two liquid phases, the viscosity of solvents, the surface tension, the flow rate of the mobile phase, the diameter of the inlet tip and the internal diameter of the column. In general, small-bore columns (less than $1.0 \mathrm{~mm}$ ) produce flow plugs in which the entire contents of the tube are displaced. On the other hand, it should be noted that a large diameter of the tubes decreases the efficiency of separation. An internal column diameter of about $2 \mathrm{~mm}$ seems to be ideal. We have used numerous solvent systems, among them, some were not indicated [11]. The system methanol-hexane-water which is frequently used in the
Crasc counter-current distribution produces flow plugs which result in the displacement of the stationary phase by the mobile phase. Another unsuitable solvent system was $n$-butanol-pyridine-water which gave no droplets due to its high viscosity. We obtained good results by using $\quad \mathrm{CHCl}_{3} / \mathrm{MeOH} / \mathrm{H}_{2} \mathrm{O}, \quad \mathrm{CH}_{2} \mathrm{Cl}_{2} /$ $\mathrm{MeOH} / \mathrm{H}_{2} \mathrm{O}$ or $\mathrm{CHCl} / \mathrm{MeOH} / \mathrm{PrOH} /$ $\mathrm{H}_{2} \mathrm{O}$ mixtures in different proportions. Modification of the amount of $\mathrm{MeOH}$ in a given mixture leads to a large change in the polarity of the system. The solvent systems used so far to give a suitable size of droplets for efficient separation are given in Table I. Most of them are tertiary or quaternary systems, one of the components being water.

A quick way to select a solvent system consists in checking the sample by thinlayer chromatography (TLC) on silica gel with the water-saturated organic layer $[11,12]$. Empirically, we found that if the $R_{i}$ values of the compounds to be separated are higher than about 0.50 (less polar solutes), the less polar layer is sui- 


\section{Table I}

Solvent systems employed in DCCC

\begin{tabular}{|c|c|c|}
\hline Separated compounds & Solvent systems & References \\
\hline saponins (triterpenoid glycosides) & $\begin{array}{l}\mathrm{CHCl}_{3}-\mathrm{MeOH}-\mathrm{H}_{2} \mathrm{O}(7: 13: 8) \\
\mathrm{CHCl}_{3}-\mathrm{MeOH}-\mathrm{H}_{2} \mathrm{O}(5: 6: 4) \\
\mathrm{CHCl}_{3}-\mathrm{MeOH}-\mathrm{n}-\mathrm{PrOH}-\mathrm{H}_{2} \mathrm{O}(9: 12: 1: 8) \\
\mathrm{CHCl}_{3}-\mathrm{C}_{6} \mathrm{H}_{6}-\mathrm{EtOAc}-\mathrm{MeOH}-\mathrm{H}_{2} \mathrm{O}(45: 2: 3: 60: 40)\end{array}$ & $\begin{array}{l}11,19,20 \\
19 \\
20 \\
25\end{array}$ \\
\hline saponins (spirostanol glycosides) & $\mathrm{CHCl}_{3}-\mathrm{MeOH}-\mathrm{H}_{2} \mathrm{O}(7: 13: 8)$ & 18 \\
\hline saponins (ginsenosides) & $\begin{array}{l}\mathrm{CHCl}_{3}-\mathrm{MeOH}-\mathrm{n}-\mathrm{PrOH}-\mathrm{H}_{2} \mathrm{O}(45: 60: 6: 40) \\
\mathrm{CHCl}_{3}-\mathrm{MeOH} \text {-iso-PrOH- } \mathrm{H}_{2} \mathrm{O}(5: 6: 1: 4) \\
\mathrm{CHCl}_{3}-\mathrm{MeOH}-\mathrm{PrOH}-\mathrm{H}_{2} \mathrm{O}(4: 6: 1: 4)\end{array}$ & $\begin{array}{l}24 \\
22 \\
21,23\end{array}$ \\
\hline cardiac glycosides & $\begin{array}{l}\mathrm{CHCl}_{3}-\mathrm{MeOH}-\mathrm{H}_{2} \mathrm{O}(5: 6: 4) \\
\mathrm{CHCl}_{3}-\mathrm{MeOH}-\mathrm{H}_{2} \mathrm{O}(5: 10: 6) \\
\mathrm{CHCl}_{3}-\mathrm{MeOH}-\mathrm{H}_{2} \mathrm{O}(5: 9: 7)\end{array}$ & $\begin{array}{l}19 \\
29 \\
29\end{array}$ \\
\hline iridoid and secoiridoid glycosides & $\begin{array}{l}\mathrm{CHCl}_{3}-\mathrm{MeOH}-\mathrm{H}_{2} \mathrm{O}(43: 37: 20) \\
\mathrm{CHCl}_{3}-\mathrm{MeOH}-\mathrm{O}-\mathrm{PrOH}-\mathrm{H}_{2} \mathrm{O}(9: 12: 1: 8)\end{array}$ & $\begin{array}{l}12 \\
12\end{array}$ \\
\hline diterpenoids & $\mathrm{CHCl}_{3}-\mathrm{MeOH}-\mathrm{H}_{2} \mathrm{O}(7: 13: 8)$ & 31 \\
\hline xanthones (glycosides) & $\mathrm{CHCl}_{3}-\mathrm{MeOH}-\mathrm{n}-\mathrm{PrOH}-\mathrm{H}_{2} \mathrm{O}(9: 12: 1: 8)$ & 12 \\
\hline xanthones (aglycones) & $\mathrm{CHCl}_{3}-\mathrm{MeOH}-\mathrm{H}_{2} \mathrm{O}(13: 7: 4)$ & 12 \\
\hline flavonoid glycosides & 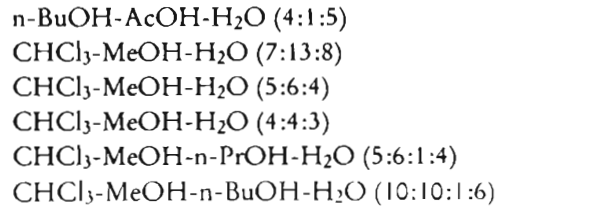 & $\begin{array}{l}11 \\
19 \\
32 \\
35,41 \\
33 \\
34\end{array}$ \\
\hline anthraquinone glycosides & $\mathrm{CHCl}_{3}-\mathrm{MeOH}-\mathrm{n}-\mathrm{PrOH}-\mathrm{H}_{2} \mathrm{O}(9: 12: 1: 8)$ & 19,20 \\
\hline chromenes, lignans & $\begin{array}{l}\mathrm{CHCl}_{3}-\mathrm{MeOH}-\mathrm{H}_{2} \mathrm{O}(5: 6: 4) \\
\mathrm{CHCl}_{3}-\mathrm{MeOH}-\mathrm{H}_{2} \mathrm{O}(4: 4: 3)\end{array}$ & $\begin{array}{l}32,40 \\
41\end{array}$ \\
\hline sugars (monosaccharides) & $\mathrm{CHCl}_{3}-\mathrm{MeOH}-\mathrm{H}_{2} \mathrm{O}(7: 13: 8)$ & 20 \\
\hline cyclitols & $\mathrm{CHCl}_{3}-\mathrm{MeOH}-\mathrm{H}_{2} \mathrm{O}(50: 57: 30)$ & 34 \\
\hline alkaloids & $\begin{array}{l}\mathrm{CHCl}_{3}-\mathrm{MeOH}-\mathrm{H}_{2} \mathrm{O}(13: 7: 8) \\
\mathrm{CHCl}_{3}-\mathrm{MeOH}-\mathrm{H}_{2} \mathrm{O}(5: 5: 3) \\
\mathrm{CHCl}-\mathrm{MeOH}-5 \% \mathrm{HCl}(5: 5: 3) \\
\mathrm{C}_{6} \mathrm{H}_{6}-\mathrm{CHCl}_{3}-\mathrm{MeOH}-\mathrm{H}_{2} \mathrm{O}(5: 5: 7: 2) \\
\mathrm{CHCl}_{3}-\mathrm{MeOH}-\mathrm{n}-\mathrm{PrOH}-\mathrm{H}_{2} \mathrm{O}(45: 60: 2: 40)\end{array}$ & $\begin{array}{l}43 \\
44,45,46 \\
46 \\
42 \\
47\end{array}$ \\
\hline DNP amino acids & $\mathrm{CHCl}_{3}-\mathrm{AcOH}-0.1 \mathrm{~N} \mathrm{HCl}(2: 2: 1)$ & 1 \\
\hline peptides & $\begin{array}{l}\mathrm{C}_{6} \mathrm{H}_{6}-\mathrm{CHCl}_{3}-\mathrm{MeOH}-\mathrm{H}_{2} \mathrm{O}(15: 15: 23: 7) \\
\mathrm{C}_{6} \mathrm{H}_{6}-\mathrm{CHCl}_{3}-\mathrm{MeOH}-0.1 \mathrm{~N} \mathrm{HCl}(11: 5: 10: 4) \\
\mathrm{CHCl}_{3}-\mathrm{MeOH}-0.1 \mathrm{~N} \mathrm{HCl}(19: 19: 12) \\
\text { sec-BuOH-TFA- } \mathrm{H}_{2} \mathrm{O}(120: 1: 160) \\
\text { n-BuOH-AcOH- } \mathrm{H}_{2} \mathrm{O}(4: 1: 5)\end{array}$ & $\begin{array}{l}48 \\
48 \\
48 \\
19 \\
50\end{array}$ \\
\hline lipids & $\begin{array}{l}\text { heptane-n- } \mathrm{BuOH}-\mathrm{CHCl}_{3}-\mathrm{MeOH}-60 \% \mathrm{AcOH} \\
(3: 2: 2: 3: 5)\end{array}$ & 51 \\
\hline sulfonoglycolipids & $\mathrm{CHCl}_{3}-\mathrm{MeOH}-\mathrm{H}_{2} \mathrm{O}(10: 12: 7)$ & 52 \\
\hline
\end{tabular}


table for use as the mobile phase. With more polar substrates $\left(R_{f}<0.50\right)$, the more polar layer should be used as the mobile phase. If the $R_{i}$ values are in the range $0.40-0.60$, the separation can be achieved by using either the more polar layer or the less polar layer as the mobile phase. This is illustrated in the following by the separation of a fraction $(60 \mathrm{mg})$ of a crude extract of a Rocky Mountains Gentiana species (Gentiana strictiflora (RYins.) A. Nis) obtained after column chromatography on Sephadex LH-20. On silica gel TLC, with $\mathrm{CHCl}_{3}-\mathrm{MeOH}$ $\mathrm{PrOH}-\mathrm{H}_{2} \mathrm{O}(9: 12: 1: 8)$, lower layer, this fraction showed two UV active spots at $R_{i}=0.35$ and 0.41 . DCCC separation by using the more polar upper layer as mobile phase yielded two pure compounds $1(32 \mathrm{mg})$ and $2(26 \mathrm{mg})$, identi-
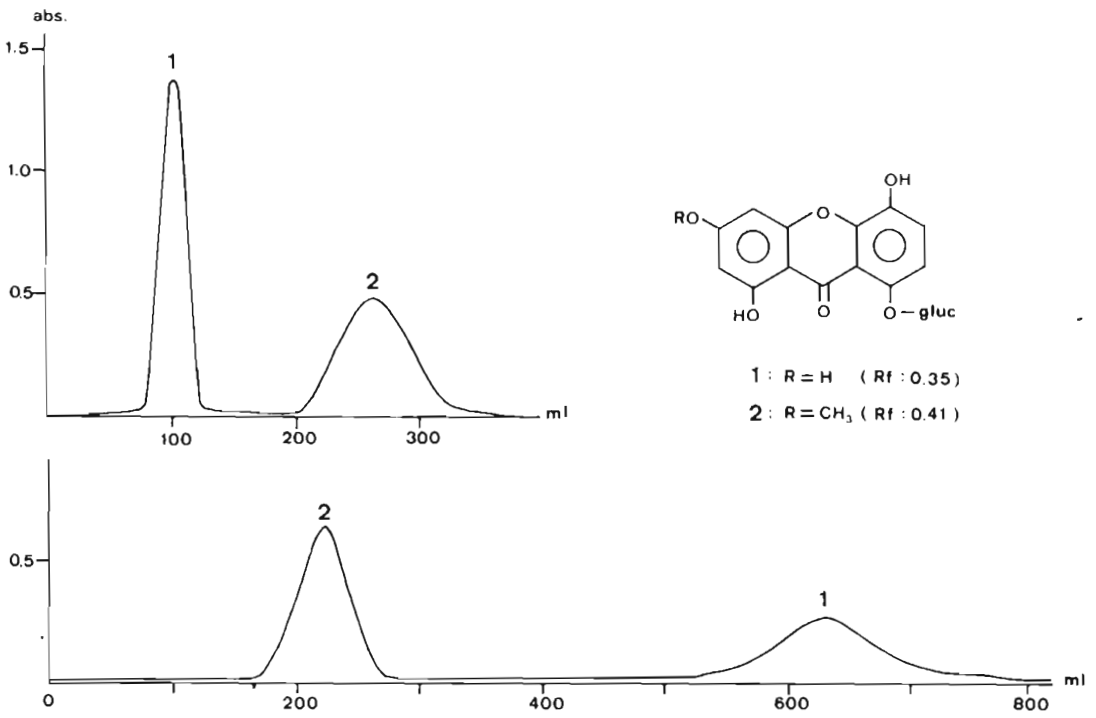

Fig. 2. UCCC separation of xanthone-O-glycosides with $\mathrm{CHCl}_{3}-\mathrm{MeOH}-n-\mathrm{PrOH}-\mathrm{H}_{2} \mathrm{O}(9: 12: 1: 8)$. Top elution curve: the mobile phase was the more polar upper layer. Bottom elution curve: the mobile phase was the less polar lower layer. fied as 1,3,5-trihydroxyxanthone-8-O$\beta$-D-glucoside and as 1,5-dihydroxy-3methoxy xanthone- 8 - $\mathrm{O}-\beta-\mathrm{D}$-glucoside by comparison with authentic samples [13] (Fig. 2, top elution curve). Both glycosides were separated with a total volume of about $350 \mathrm{ml}$ of mobile phase. As expected, the use of the more polar layer as the mobile phase resulted in earlier elution of the more polar compound 1 . For comparison, the same mixture of 1 and 2 was submitted to DCCC and eluted with the less polar lower layer. The total volume of mobile phase used for eluting both compounds was $800 \mathrm{ml}$ (Fig. 2, bottom elution curve); however, the resolution was better than in the previous run. As expected, the less polar glycoside 2 was eluted first.

These comparative experiments sug-

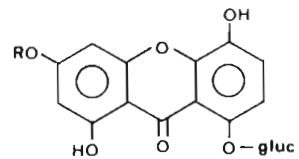

$1: R=H \quad(R f: 0.35)$

2: $R=\mathrm{CH}_{3}(\mathrm{Rf}: 0.41)$

(Reprinted from: HostFTtMANN, K., M. Ho STI: TMANN-KAI.DAS and O. SIICHIR: Helv. Chim. Acta 62, 2079 (1979)). 
gest that in the case of difficult separations, it could be better to use the liss polar layer as mobile phase for eluting compounds with relatively low $R_{i}$ values, and the more polar layer for eluting compounds with relatively high $R_{i}$ values. A better resolution will be obtained, but the separation time will be much longer. If the $R_{f}$ values of the compounds to be separated are either too low $(<0.3-0.2)$, or too high $(>0.8-0.7)$, no elution will take place in a reasonable time, although the compounds can be recovered quantitatively from the remaining stationary phase.

Solvent system selection based on TLC is very simple and rapid and gives generally satisfactory results. The adsorption effect is small by using the water-saturated organic layer as eluent and can partially be eliminated by conditioning the plate prior to development. But since DCCC depends solely on the partition coefficient, separation cannot always be predicted from the TLC behavior.

\section{Application in Natural Products Isolation}

DCCC has been applied up to now to the purification and separation of various classes of natural products from plant sources. Since there is no solid support which might cause irreversible adsorption, DCCC has been used especially for the isolation of polar plant constituents such as glycosides which are often very difficult to separate.

\section{Saponins}

Triterpene glycosides and spirostanol glycosides are widely distributed and form one of the most important group of naturally occurring glycosides. They exihibit various biological and pharmacological activities and the interest in these compounds is still growing. The methods for the separation of saponins have been reviewed by Hır. et al. [14, 15] and consist mainly in column chromatography on silica gel, cellulose or Sephadex. Frequently, the column chromatographic separation requires solvent gradients which are very time consuming. Counter-current distribution is not indicated as the shaking device causes formation of foams. This is avoided in DCCC and thus this technique is ideal for the isolation of saponins. During the course of our systematic isolation and structural studies on biologically active compounds from medicinal plants, we found several species possessing strong molluscicidal properties. Plants showing this activity are currently receiving considerable attention as potential agents for the control of bilharzia. We used DCCC for the isolation of the active principles of common ivy berries, Hedera belix (Araliaceae) [11]. The fresh berries were extracted with $70 \%$ ethanol. After concentration, this extract was partitioned between nbutanol and water. The $n$-butanol layer (1.2 g) exhibiting the biological activity was submitted to DCCC using $\mathrm{CHCl}_{3}$ $\mathrm{MeOH}-\mathrm{H}_{2} \mathrm{O}$ (7:13:8) as solvent (mobile phase: the less polar lower layer) and the fractions were monitored by TLC. This gave five fractions as shown in Fig. 3. Fractions 1 which was eluted with the solvent front was still a mixture of the least polar components (i.e., fatty acids, chlorophylls, etc.) of the crude extract, whereas four pure compounds 2-5 were obtained (shaded area in Fig. 3). No 


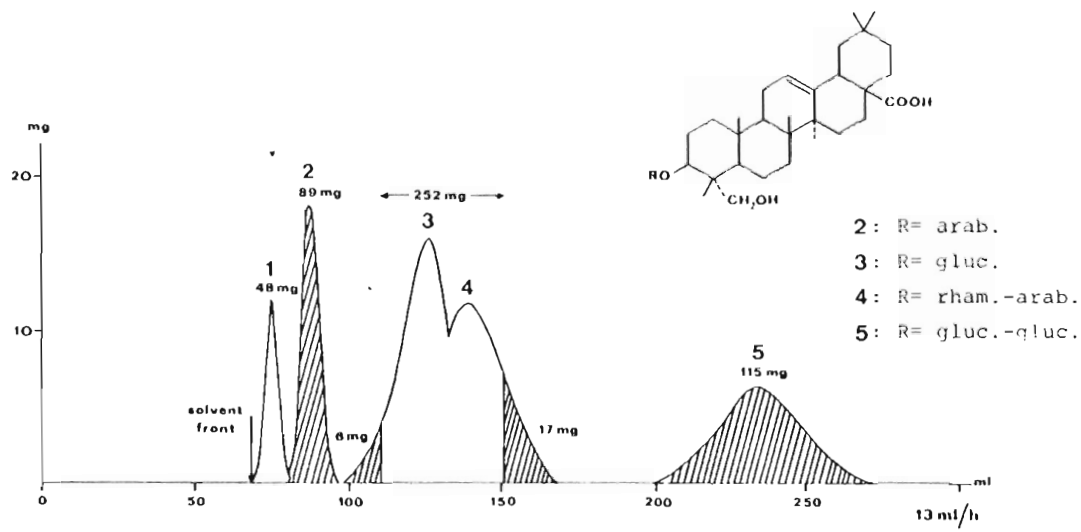

Fig. 3. DCCC of a crude extract of Hedera helix berries (1.2 g) with $\mathrm{CHCl}_{3}-\mathrm{McOH}-\mathrm{H}_{2} \mathrm{O}(7: 13: 8)$; mobile phase, lower layer (Rcprinted from: $\mathrm{H}_{0}$.

STH:TTMANN K., M. HOSTHTTMANN-KalDAS and K. NAKANiSHI: J. Chromatogr. 170, 355 (1979)).

base line separation could be achieved for compounds 3 and 4 with the conditions employed in the present experiment. After elution of compound 5 , about $670 \mathrm{mg}$ of the most polar components (free sugars, polysaccharides, etc.) were recovered from the stationary phase of the apparatus. The pure compounds were identified by means of spectroscopic studies (FD-MS, 'H-NMR and ${ }^{13} \mathrm{C}-\mathrm{NMR}$ ) as glycosides of hederagenin [16]. The structure determination of these triterpenoid saponins will be published shortly along with the results of the biological tests [17].

As expected by usage of the less polar layer as mobile phase, the glycosides $2-5$ were eluted in order of increasing polarity. In the present case, major plant constituents were obtained directly in pure form from a crude extract with a very small solvent consumption.

However, when the active principle of a plant is a minor constituent, it is preferable to inject an enriched fraction into DCCC. We illustrated this by isolating

the molluscicidal principle from the methanolic bark exiract of dogwood, Cornus florida (Cornaceae) [18].

A very active fraction, obtained after gel filtration of the crude extract, was submitted to DCCC (same conditions as above) and afforded three base-line separated spirostanol glycosides identified as sarsapogenin - $\beta$-1)-galactopyranoside, sarsapogenin - $\mathrm{O}-\beta-1)-x y l o p y r a n o s y l-(1$ $\rightarrow 2)$ - $\beta$-(1)-galactopyranoside and sarsapogenin-O- $(3-1)$-glucopyranosyl- $(1 \rightarrow 2)$ $\beta$-1)-galactopyranoside. The entire separation was achieved in less than $8 \mathrm{~h}$ and the total volume of mobile phase used for the elution was $100 \mathrm{ml}$, whereas no efficient preparative scale separation could be made either by open column chromatography or TLC.

The saponins of the seeds of Zizyphus jujuba and the bark of Hovenia dulcis were successfully separated by $\mathrm{T}_{\text {ANINLRA }}$ et al. $[19,20]$ who used $\mathrm{CHCl}_{3}-\mathrm{MeOH}$ $\mathrm{H}_{2} \mathrm{O}(7: 13: 8)$ and $\mathrm{CHCl}_{3}-\mathrm{MeOH}-\mathrm{n}-$ $\mathrm{PrOH}-\mathrm{H}_{2} \mathrm{O}(9: 12: 1: 8)$ as solvent systems in the ascending mode (mobile 
phase: upper layer). In the course of the chemical investigation of the well-known Chinese longevity drug ginseng (the root of Panax ginseng), $\mathrm{T}_{\wedge \mathrm{N} \wedge \mathrm{K} A}$ et al. $[21,22$, 23] used DCCC in combination with other chromatographic techniques for the isolation of closely related dammaranetype saponins. A quantitative determination of ginsenosides in several ginseng species has been reported by Otsuka et al. [24]. These authors fractionated the crude butanol extracts by DCCC and treated each fraction with phenol/ $\mathrm{H}_{2} \mathrm{SO}_{4}$. The characteristic orange colour obtained was determined photometrically at $490 \mathrm{~nm}$. The same procedure was applied to the quantitative determination

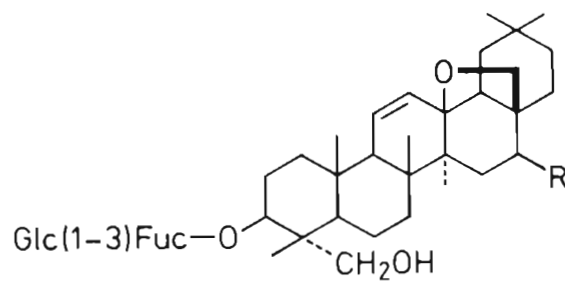

R: $\quad \beta O H$ Saikosaponin a

$R$ : $\alpha O H$ Saikosaponin $d$ of saikosaponins in the roots of Bupleurum falcatum (Umbelliferae) and its congeners [25]. By using $\mathrm{CHCl}_{3}-\mathrm{C}_{6} \mathrm{H}_{6}-\mathrm{EtO}$ Ac- $\mathrm{MeOH}-\mathrm{H}_{2} \mathrm{O} \quad(45: 2: 3: 60: 40)$ as solvent in the ascending mode, a base-line separation of saikosaponins $a, b$ and $c$ was obtained. (Fig. 4)

As expected by usage of the more polar layer as mobile phase, saikosaponin c was eluted before saikosaponins a and $\mathrm{d}$. The separation of saikosaponin $\mathrm{c}$ with a trisaccharide sugar moiety from saikosaponins a and $d$ possessing two sugars can readily be performed by column chromatography, but the separation of the latter two saponins which differ only in the configurations at $\mathrm{C}-16-\mathrm{OH}$ is very diffi-

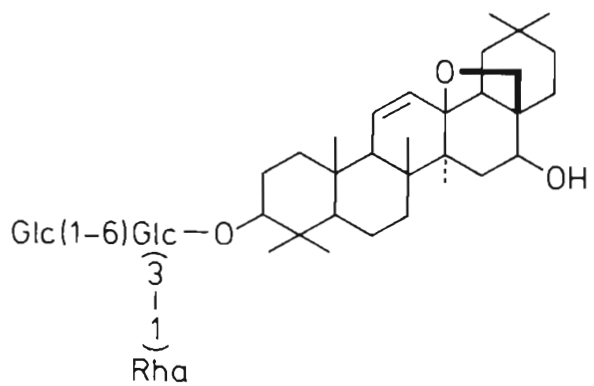

Saikosaponin c

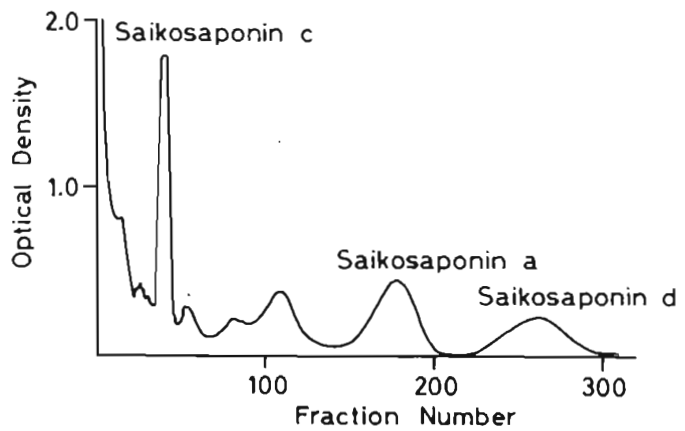

Fig. 4. DCCC of an extract of wild-growing $B u$ pleurum longiradiatum with $\mathrm{CHCl}_{3}-\mathrm{C}_{6} \mathrm{H}_{6}-\mathrm{ErO}$ Ac- $\mathrm{MeOH}-\mathrm{H}_{2} \mathrm{O}(45: 2: 3: 60: 40)$ by the ascending method.
(Reprinted from: OTSI:KA, H., S. KOBAYASHI and S. Shibata: Planta med. 33, 152 (1978)). 
cult to achieve by the usual method (i.e. one single spot on TLC). Recently, a high performance liquid chromatography (HPLC) study of Bupleuri Radix (Bupleurum falcatum) has been reported [26]. The genuine saikosaponins containing the unstable allyloxide linkage were converted into artificial diene-saponins by mild acid treatment and separated by reverse-phase chromatography on a column of octadecylsilylated silica gel with $\mathrm{MeOH}-\mathrm{H}_{2} \mathrm{O}-\mathrm{AcOH}-(\mathrm{Et})_{3} \mathrm{~N}$ $(75: 25: 0.2: 0.2)$. The separation of the stereoisomers obtained by DCCC was comparable, even better, than the one obtained by HPLC. But for quantitative analysis, HPLC is, of course, a much more rapid method.

By repeated column chromatography and DCCC, IsHII et al. [27], isolated ten closely related oleanene-type saponins from the roots of Platycodon grandiflorum. Solvent systems formed of $\mathrm{CHCl}_{3}$ $\mathrm{MeOH}-\mathrm{H}_{2} \mathrm{O}$ are well indicated for the separation of various types of saponins and can be used either in the ascending mode (very polar saponins) or in the descending mode (saponins possessing one or two sugars and few free hydroxyl groups). We used the relatively weakly polar system $\mathrm{CHCl}_{3}-\mathrm{MeOH}-\mathrm{H}_{2} \mathrm{O}$ (65:35:20) in the descending mode for the isolation of triterpenes such as oleanolic acid from Gentiana species [28].

\section{Cardiac glycosides}

Cardenolides being structurally related to saponins, the above mentioned solvent systems can be used. During the course of re-investigation of the cardiac glycosides of Nerium oleander (Apocynaceae), Abi: and Yamauchi [29] isolated new glycosides with an unusual framework.
The crude leaf extract was first fractionated by silica gel column chromatography into biosides and triosides. The fraction containing the biosides was subjected to DCCC using $\mathrm{CHCl}_{3}-\mathrm{MeOH}$ $\mathrm{H}_{2} \mathrm{O}(5: 10: 6)$ by the ascending method and afforded compounds $I$ and 2 . The more polar triosides 3 and 4 were separated with $\mathrm{CHCl}_{3}-\mathrm{MeOH}-\mathrm{H}_{2} \mathrm{O}(5: 9: 7$, ascending).

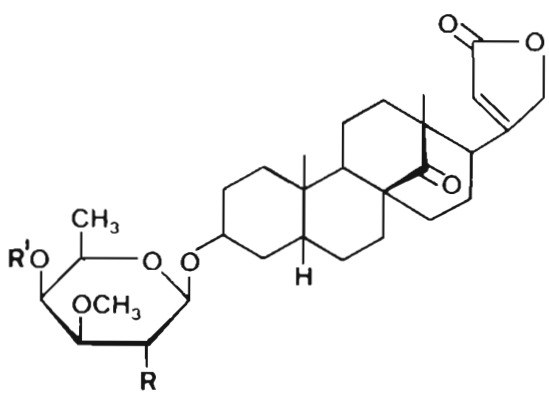

1: $R=H, R^{\prime}=\beta$-D-glucosyl

3: $R=H, R^{\prime}=\beta-D$-gentiobiosyl

3: $\mathrm{R}=\mathrm{OH}, \mathrm{R}^{\prime}=\beta$-D-glucosyl

4: $\mathrm{R}=\mathrm{OH}, \mathrm{R}^{\prime}=\beta$-D-gentiobiosyl

A purification of digitonin was achieved by TAximka et al. [19] with $\mathrm{CHCl}_{\text {:- }}$ $\mathrm{MeOH}-\mathrm{H}_{2} \mathrm{O}(5: 6: 4)$ in the ascending mode.

\section{Iridoid and secoiridoid glycosides}

We applied DCCC to the isolation of iridoid glycosides from Ajuga pyramidalis (Labiatae) [12]. The crude butanol extract $(1.4 \mathrm{~g})$ was fractionated with $\mathrm{CHCl}_{3}-\mathrm{MeOH}-\mathrm{H}_{2} \mathrm{O}(43: 37: 20)$ by the ascending method. This resulted in three major fractions (Fig. 5). The fraction eluted with the solvent front ( $680 \mathrm{mg}$ ) was a mixture of the most polar constituents, whereas fractions 1 (114 mg) and 2 (508 


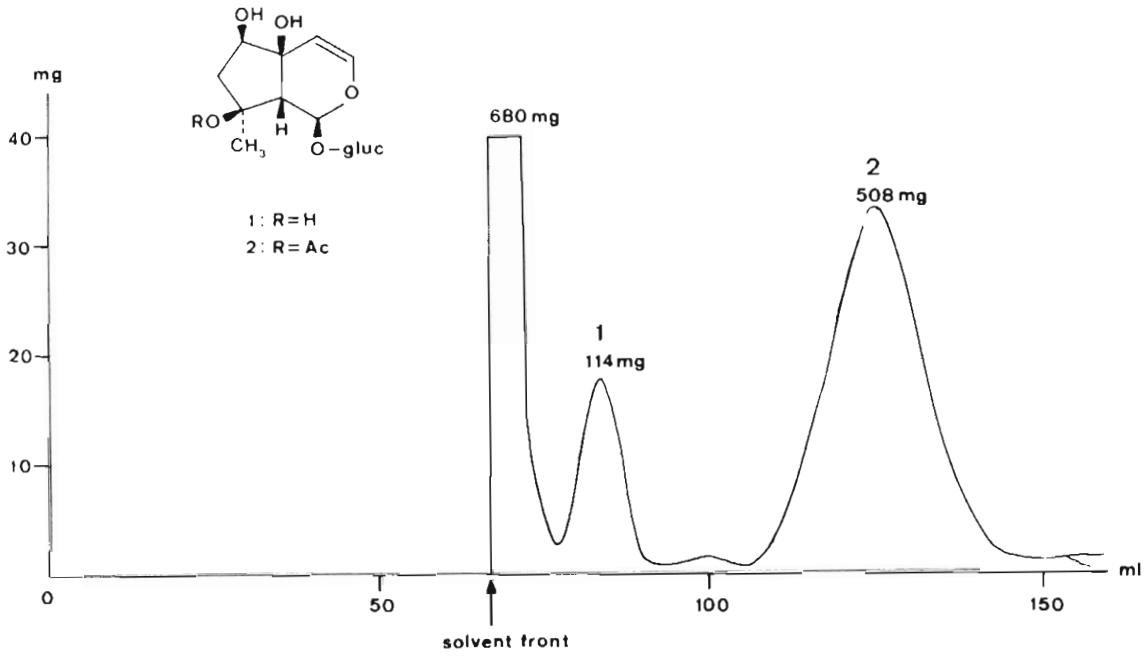

lig. 5. DCCC of a crude extract of Ajuga pyramidulis $\left(1.4\right.$ g) with $\mathrm{CHCl}_{3} \cdot \mathrm{McOH}-\mathrm{H}_{2} \mathrm{O}(43: 37: 20)$ by the ascending method (mobile phase: upper lay er).

(Reprinted from: Hostitimail K.. M. HoxtiTH WaiN KAldas and O. SHCHr: Helv. Chim. Acta 62. $2079(1979)\}$.

$\mathrm{mg}$ ) showed single spots on TLC. The pure compounds were identified by means of spectroscopic studies as harpagide and 8-O-acerylharpagide, respectively. The entire isolation process required only about $8 \mathrm{~h}$ and the total amount of solvent used for the elution was less than $150 \mathrm{ml}$. From the remaining stationary phase, $94 \mathrm{mg}$ of a mixture of minor constituents could be recovered.

Gentiopicrin, one of the bitter principle of Gentiana, and related secoiridoid glycosides have also been isolated by DCCC [12]. The solvent consumption for separation by preparative HPLC on the same scale was much higher. HPLC is very fast, but requires tedious purifications of the sample prior to injection in order to avoid column contamination [30].

From a Castilleja species (Scruphulariaceae) collected in Colorado, we obtai-

ned after column chromatography on Sephadex $\mathrm{LH}-20$ a fraction containing minor iridoid constituents. This fraction, when submitted to DCCC, gave four nearly pure glycosides. Final purification was achieved by semipreparative HPLC on a $\mathrm{C}_{1 \mathrm{~s}}$ chemically bonded silica gel with $\mathrm{MeOH}-\mathrm{H}_{2} \mathrm{O}$. Spectroscopic studies on the pure compounds indicate that they are closely related to loganin and dihydrocornin. The structure determination is currently under investigation and will be published shortly.

$\mathrm{CHCl}_{3}-\mathrm{MeOH}-\mathrm{H}_{2} \mathrm{O}$ mixtures were found to be ideal for the separation of this class of glycosides. For iridoid glycoside esters, it is desirable to use the less polar lower layer as mobile phase.

\section{Diterpenoids}

Only one example of separation of weakly polar compounds by DCCC has be- 


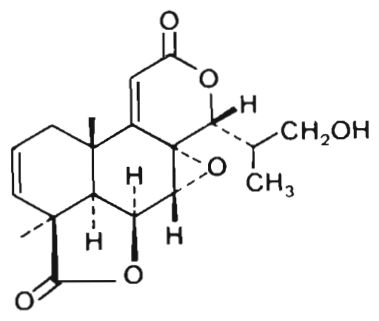

1

en reported up to now, namely the isolation of cytotoxic nor-diterpenoid dilactones from Podocarpus nagi [31]. Compounds $I$ and 2 both showed very similar chromatographic behaviors and could not be separated by TLC nor by HPLC. Only a combined technique of adsorption chromatagraphy with DCCC gave a satisfactory separation of 1 and 2 . The solvent system used was $\mathrm{CHCl}_{3}-\mathrm{MeOH}$ $\mathrm{H}_{2} \mathrm{O}(7: 13: 8)$ in the descending mode.

\section{Polyphenols (flavonoids, xanthones, ca-} techins, anthraquinones, chromenes, lignans)

The acidic hydroxyl groups in polyphenols often cause irreversible adsorption on the solid sationary phase during the column chromatographic procedure. This can be partially avoided by adding an acid to the mobile phase and is useful for analytical work. However when developing a preparative scale separation, the use of acid as one of the components of the mobile phase is not always indicated. The risk of sample deterioration, i.e. hydrolysis of glycosides, is increased during the long operation and the recovery of the sample from the relatively large volume of eluent.

$\mathrm{CHCl}_{3}-\mathrm{MeOH}-\mathrm{H}_{2} \mathrm{O}$ mixtures in different proportions have been used for the separation of various classes of polyphe-

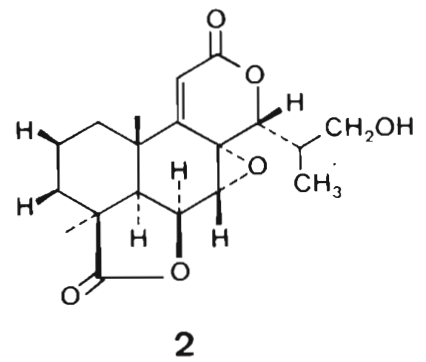

nolic glycosides by DCCC. For flavonoids and related compounds bearing few hydroxyl groups and one sugar or aglycones possessing several free hydroxyl groups, the separation can be achieved by using the less polar lower layer as mobile phase (descending mode), whereas the more polar layer is suited for more polar monosaccharides or disaccharides.

For example, from a crude fraction of Tecoma stans (Bignoniaceae), we were able to isolate within $6 \mathrm{~h}$ a pure glycoside identified as quercetin-3-O-glucoside using the upper layer of $\mathrm{CHCl}_{3}-\mathrm{MeOH}-$ $\mathrm{H}_{2} \mathrm{O}(7: 13: 8)$ as mobile phase [11]. For the separation of very polar flavone gly. cosides, we used n-BuOH-AcOH-H,O (4:1:5), but the separation time was long, due to the high viscosity of this solvent system [11]. DCCC has also been applied to the isolation of flavone-C-glycosides from various plant sources (Table II).

A remarkable separation has been recently reported by Tavaka et al. [35]. They isolated 3 "-O-acetyl-quercitrin (I) and 4"-O-acetyl-quercitrin (2) from the aerial parts of Pteris grandifolia (Pteridaceae) using $\mathrm{CHCl}_{3}-\mathrm{MeOH}-\mathrm{H}_{2} \mathrm{O}(4: 4: 3)$ in the ascending mode (mobile phase: upper layer).

A base-line separation of 1 and 2 was obtained.

Separations of isomeric acylated flavono- 


\section{Table II}

$\mathrm{C}$-glycosides isolated by DCCC.

\begin{tabular}{llll}
\hline C-glycoside & plant source & solvent & Ref. \\
\hline swertisin & Zizyphus jujuba & $\mathrm{CHCl}_{3}-\mathrm{MeOH}-\mathrm{H}_{2} \mathrm{O}(7: 13: 8)$ & 19 \\
vitexin & Lindsaea ensifolia & $\mathrm{CHCl}_{3}-\mathrm{MeOH}-\mathrm{H}_{2} \mathrm{O}(5: 6: 4)$ & 32 \\
isoorientin & Gentiana strictiflora & $\mathrm{CHCl}_{3}-\mathrm{MeOH}-\mathrm{nPrOH}-\mathrm{H}_{2} \mathrm{O}(5: 6: 1: 4)$ & 33 \\
6,8-di-C-pentosyl & Lespedeza cuneata & $\mathrm{CHCl}_{3}-\mathrm{MeOH}-\mathrm{n}-\mathrm{BuOH}-\mathrm{H}_{2} \mathrm{O}$ & 34 \\
apigenin & & $(10: 10: 1: 6)$ & \\
\hline
\end{tabular}

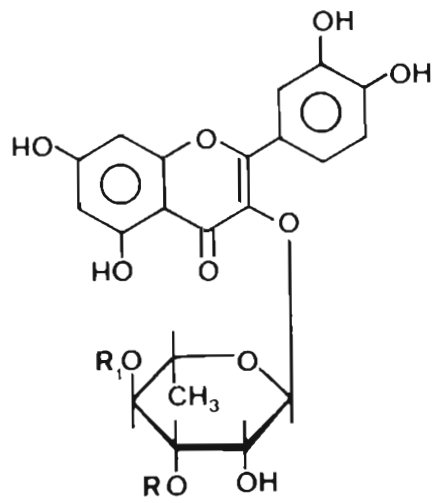

1: $\mathrm{R}=\mathrm{Ac}, \mathrm{R}_{1}=\mathrm{H}$

2: $R=H, R_{1}=A c$

id glycosides are usually very difficult to achieve, even by HPLC. Thus, DCCC opens new possibilities and will be of great help in the future for all chemists interested in flavonoids.

The structures of xanthones are related to that of flavonoids and their chromatographic behaviour is similar. There is at present great interest in these compounds since Suzukı et al. [36] demonstrated that xanthones isolated from GinTiana inhibit rat brain mitochondrial monoamine oxidase (MAO) in vitro. In connection with our systematic investigation on xanthones from GI:NTiNsi, we studied several North-American species. The crude chloroform extract (200 mg) of Gentiana strictiflora was submitted to DCCC with $\mathrm{CHCl}_{3}-\mathrm{MeOH}-\mathrm{H}_{2} \mathrm{O}$ 66:35:20, descending mode) [12]. Three fractions were obtained (Fig. 6). The less polar constituents (colour pigments, fatty acids, triterpenes) were not separated under the chosen conditions and were eluted with the solvent front, whereas fraction $1(29 \mathrm{mg})$ and $2(10 \mathrm{mg})$ showed single spots on TI.C. Spectroscopic studies of the pure compounds led to the structure of bellidifolin and desmethyl-bellidifolin, respectively. These xanthone aglycones were separated far more readily than by column chromatography and with a smaller solvent consumption (the total amount of mobile phase used being 160 $\mathrm{ml}$ ).

The above mentioned solvent system is indicated for the separation of other kinds of non glycosidic phenolics. We employed it for the isolation of the red colour pigments of a crude extract of $\mathrm{Hy}$ pericum perforatum (common St. John's wort) [37]. Both, the ascending and the descending modes, furnished hypericin and pseudohypericin [38] in a pure form. Among other polyphenolics successfully separated by DCCC, we have to mention the isolation of an unstable catechin glycoside from Dalbergia nitidula (Leguminosae) [11], the separation of sennosi- 


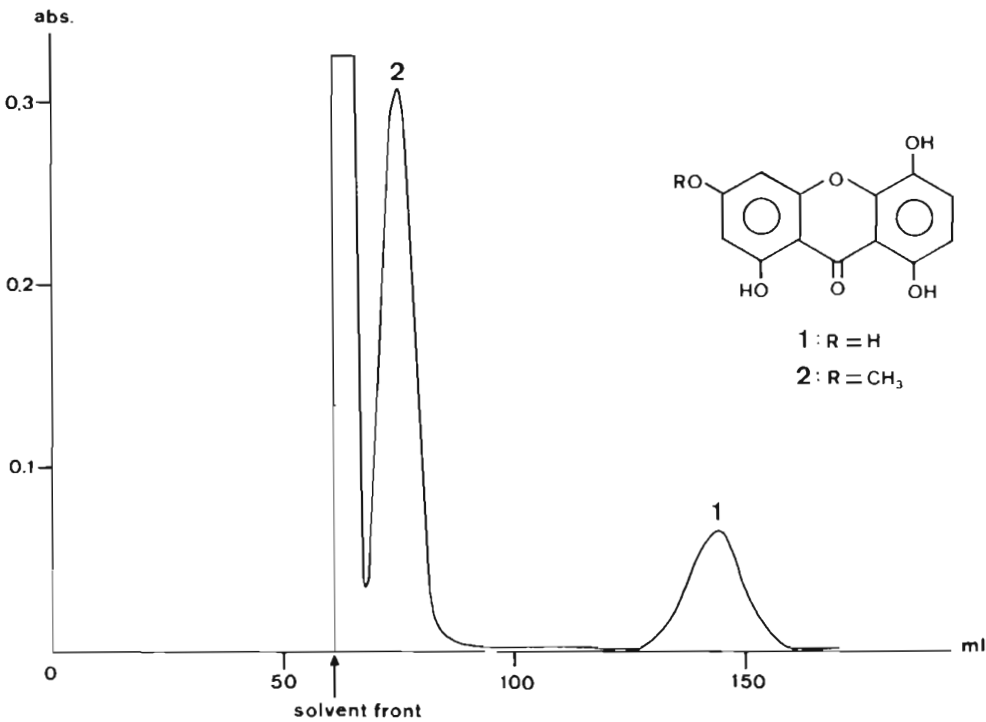

Fig. 6. DCCC of a crude chloroform extract of Gentiuna strictiflora with $\mathrm{CHCl}_{3}-\mathrm{MeOH}-\mathrm{H}_{2} \mathrm{O}$ (13:7:4) in the descending mode (mobile phase: lo-

(Reprinted from: HostrtimaiN, K., M. Ho STITMANN-Kal IJAs and O. STICHIR: Hels. Chim. Acta 62, 2079 (1979)). wer layer).

des (bisanthrone glycosides) from rhubarb $[19,20]$, the purification of lucidin primeveroside from cell cultures of $\mathrm{Ga}$ lium mollugo [38] and the isolation of $\mathrm{li}$ gnans [40] and chromenes [32, 41] from various Pteridaceae species. All these separations could be achieved by using $\mathrm{CHCl}_{3}-\mathrm{MeOH}-\mathrm{H}_{2} \mathrm{O}$ or $\mathrm{CHCl}_{3}-\mathrm{MeOH}-$ n- $\mathrm{PrOH}-\mathrm{H}_{2} \mathrm{O}$ as solvent systems.

\section{Carbohydrates and Cyclitols}

A satisfactory separation of naturally occurring monosaccharides (arabinose, xylose, galactose, glucose, fucose and rhamnose) was obtained by Ocinnr^ et al. [20] with $\mathrm{CHCl}_{3}-\mathrm{MeOH}-\mathrm{H}_{2} \mathrm{O}$ $(7: 13: 8)$ in the ascending mode. The number of theoretical plates obtained in this separation was 1200 . As a part of works to isolate biologically active substances to insects from plants, NLMATA et al. [34] studied the feeding stimulants for larvae of the yellow butterfly Eurema hecabe mandarina. They isolated from the leaves of Lespedeza cuneata two active compounds identified as myo-inositol and D-pinitol.

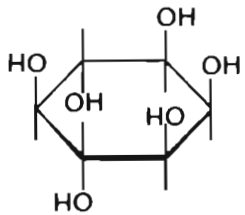

myo-inositol

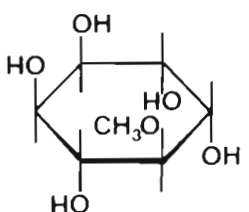

D-pinitol
A crude fraction $(1.549 \mathrm{~g})$ was submitted to DCCC with $\mathrm{CHCl}_{-}-\mathrm{MeOH}_{-} \mathrm{H}_{2} \mathrm{O}$ 
(50:57:30; descending mode) and afforded first D-pinitol (1.287 g) and then myo-inositol $(0.212 \mathrm{~g})$.

\section{Alkaloids}

The benzylisoquinoline alkaloid coclaurin was isolated from the root bark of Zizyphus jujuba with a $\mathrm{CHCl}_{3}-\mathrm{MeOH}$ $\mathrm{H}_{2} \mathrm{O}$ system [42]. We used this solvent system for the separation of the main opium (Papaver somniferum) alkaloids [43]. As the extract consisted of components with a wide range of polarity, the separation had to be achieved in two steps. A first run with the more polar upper layer as the mobile phase afforded crude morphine, a mixture of narceine and codeine and pure thebaine. After elution of thebaine, the remaining stationary phase, consisting of the less polar benzylisoquinoline alkaloids was recovered. A second run with the less polar lower layer resulted in the separation of narcotine and papaverine. The two-step separation has been avoided by $\mathrm{T}_{\mathrm{AN}}$ et al. $[44,45,46]$ who modified the $\mathrm{pH}$ of the mobile phase during the elution. With this method they obtained a good resolution of highly complex alkaloid mixtures from Papaveraceous plants. For example, from Corydalis ophiocarpa, two new protoberberine alkaloids were isolated together with known alkaloids [46]. Up to $5 \mathrm{~g}$ of sample was submitted to $\mathrm{DCCC}$ with $\mathrm{CHCl}_{3}-\mathrm{MeOH}-\mathrm{H}_{2} \mathrm{O}$ (50:55:30; McIlvain buffer solution, $\mathrm{pH} 7)$ by the ascending method. In the course of the elution, the aqueous mobile phase was replaced first by the upper layer of $\mathrm{CHCl}_{3}-\mathrm{MeOH}-\mathrm{H}_{2} \mathrm{O} \quad$ (50:55:30; McIlbain buffer solution, $\mathrm{pH} 3$ ) and finally by the upper layer of $\mathrm{CHCl}_{3}$-Me$\mathrm{OH}-5 \% \mathrm{HCl}(50: 55: 30)$, resulting in a quick and good separation of numerous alkaloids.

In the course of a biosynthetic study of the alkaloids of Cephaelis ipecacuanha (Rubiaceae), Nacaklika et al. [47] used DCCC for the purification of ipecoside with $\quad \mathrm{CHCl}_{3}-\mathrm{MeOH}-\mathrm{n}-\mathrm{PrOH}-\mathrm{H}_{2} \mathrm{O}$ $(45: 60: 2: 40)$ in the ascending mode.

\section{Application in Biochemistry}

The first separation reported by the inventors of DCCC, TA.vimLiRA et al. [1], was a high resolution of dinitrophenyl (DNP) amino acids. The solvent system was $\mathrm{CHCl}_{3}-\mathrm{AcOH}-0.1 \mathrm{~N} \mathrm{HCl}(2: 2: 1)$ used in the ascending mode. DCCC is also indicated for the purification of peptides. Оклмсто еe al. [48] fractionated crude gramicidin into pure gramicidins A, B and $C$ and a partially purified tyrocidine into pure tyrocidines $\mathrm{A}, \mathrm{B}$ and $\mathrm{C}$ with $\mathrm{C}_{b}$ $\mathrm{H}_{6}-\mathrm{CHCl}_{3}-\mathrm{MeOH}-0.1 \mathrm{~N} \mathrm{HCl}$ $(11: 5: 10: 4), \quad \mathrm{C}_{6} \mathrm{H}_{6}-\mathrm{CHCl}_{3}-\mathrm{MeOH}-\mathrm{H}_{2} \mathrm{O}$ $(15: 15: 23: 7)$ or $\mathrm{CHCl}_{3}-\mathrm{MeOH}-0.1 \mathrm{~N}$ $\mathrm{HCl}$ (19:19:12). The lower layer was used as mobile phase (descending mode) with a flow rate of $12-15 \mathrm{ml} / \mathrm{h}$. NAKAMM.M. et al. [49] obtained pure fowl angiotensin from a partially purified peptide. Kallidin, bradykinin and angiotensin were separated with sec-BuOH-trifluoroacetic acid- $\mathrm{H}_{2} \mathrm{O}(120: 1: 160)$, mobile phase: lower layer [19]. A mixture of three similar peptides was separated by Takahashi et al. [50] with $\mathrm{n}-\mathrm{BuOH}-\mathrm{AcOH}-\mathrm{H}_{2} \mathrm{O}$ (4:1:5). It appears from their work that DCCC could be a suitable method for the separation of synthetic oligopeptides.

A fractionation of human serum lipids has been reported by Konobu et al. [51]. With heptane-n- $\mathrm{BuOH}-\mathrm{CHCl}_{3}-\mathrm{MeOH}$ - 
AcOH $60 \%(3: 2: 2: 3: 5)$, a base-line separation of triolein, palmitic acid, capric acid and lecithin was achieved by the ascending method. In the course of the study of the metabolites of Anthocidaris crassispina (sea urchin), Kitaciaw et al. [52] isolated a sulfonoglycolipid from the shell by usage of DCCC in combination with column chromatography on silica gel.

\section{Advantages and Limits of the Method}

DCCC has proved to be an efficient and reproducible technique for the purification and separation of natural products. Quantities ranging from about 1 $\mathrm{mg}$ up to $4 \mathrm{~g}$ can easily be handled. Since there is no solid support which might cause irreversible adsorption, the sample is recovered quantitatively. This is of particular interest when isolating biologically active compounds because the activity is frequently lost during the timeconsuming column chromatography process. In contrast to the conventional counter-current distribution (CCD) method, no shaking is involved and hence, there is no formation of foams; furthermore, as there is no space for atmospheric oxygen in the apparatus, aerial oxidation of sensitive compounds can be avoided. Crude plant extracts can be injected without preliminary purification. This would cause column contamination if the separation is achieved by preparative HPLC. It is noteworthy that the solvent consumption is much smaller than with other chromatographic techniques such as CCD, preparative HPLC or open column chromatography. The resolution is not comparable with HPLC, however $1000-1500$ theoretical plates can easily be obtained, depending on the number of columns used.

Since a given solvent system. can be employed either in the ascending or in the descending mode, compounds with a large range of polarity can be separated. With buffer solution, modification of the $\mathrm{pH}$ during the elution is possible [45, 46]. Water being a component of the solvent systems employed up to now, DCCC has been applied mainly to glycosides and other polar compounds. An example of separation of weakly polar diterpene dilactones has been reported [31]. We are currently attempting to find solvent systems without water which form suitable droplets. So far, a solvent system which is suited for various kinds of separations is formed of $\mathrm{CHCl}_{3}-\mathrm{Me}$ $\mathrm{OH}-\mathrm{H}_{2} \mathrm{O}$ in different proportions (Table I). A list of some other solvents for DCCC has been published by Ocinara et al. [20]. Systems containing butanol are working, but the separation time is increased due to the high viscosity of this solvent.

The operation of a DCCC instrument is simple and requires little training. When a separation is completed, cleaning is made by flushing all the tubings with the stationary phase for the next analysis. However, we observed that after several months, by using similar solvent systems, the droplet formation became poor. It was necessary to flush the tubings with an appropriate detergent. The operating pressure and the flow rate depend on the solvent system and are about $5-15 \mathrm{~kg} / \mathrm{cm}^{2}$ and $8-25 \mathrm{ml} / \mathrm{h}$, respectively. Thus, the separation time is relatively long. An operation, including the filling 
of the instrument with stationary phase, requires at least $12-18 \mathrm{~h}$ depending on the number of columns employed. It can last for several days, but should not exceed one week. Solvent systems which give relatively rapid separations should be selected in order to minimize the risk of sample deterioration. When the sample contains UV active compounds, continuous-flow detection can easily be made by an appropriate detector. The use of a refractive-index detector is not indicated as sometimes small amounts of stationary phase are also eluted, resulting in an unstable base-line. In the course of our saponins and iridoids separations, the obtained fractions were monitored by TLC, a commonly used procedure for column chromatography analysis.

Although DCCC is simple and separates various types of compounds in a preparative scale with a good resolution, it possesses limitations arising from the fact that the efficiency of the method depends entirely upon droplet formation. To challenge these problems Iro et al. $[5,6$, 7,53 ] devised new systems based only on liquid-liquid partition. The emerging technique seems to be the coil planet centrifuge $[53,54]$ which is a method of counter-current chromatography employing a long column of vertical helical tubings in a centrifugal field. The separation time is thus reduced to several hours, the resolution is high, but the instrumentation is more complicated.

DCCC seduces by its simplicity and its economical operation (no expensive column packing material and very small solvent consumption). It will not replace the usual chromatographic methods, but is complementary. Used alone or in combination with column chromatography and HPLC, it is of great help for the preparative scale separation of polar natural products.

\section{References}

1. Tanimura, T., J. J. Pisano, Y. Ito and R. L. Bowman: Science 169, 54 (1970).

2. Hunt, B. J. and W'. Rigby: Chem. Ind. (London) $1868,(1967)$.

3. Still, W. C., M. Kahn and A. Mitra: J. Org. Chem. 43, 2923 (1978).

4. Hostettmann, K., M. J. Pettci, I. Kubo and K. Nakanishi: Helv. Chim. Acta 60, 670 (1977).

5. Ito, Y. and R. L.. Bowman: J. Chromatogr. Sci. 8,315 (1970)

6. Ito, Y. and R. L. Bowman: Anal. Chem. 43, 69A (1971).

7. Ito, Y., R. F. Hurst, R. L. Bowman and F. K. Achter: Separation and purification methods 3 . 133 (1974).

8. Craig, L. C., in: R. Alexander and R. J. Block, (eds.), Analytical Methods of Protein Chemistry, Vol. 1, pp. 121-160, Oxford 1960, Pergamon Press.

9. Craig, L. C. and J. Sogn: Methods of Enzymology, Vol. 43, pp. 320-346, New York 1975, Academic Press.

10. Hecker, E.: Verteilungsverfahren im Laboratorium, Weinheim/Bergstraße 1955, [Verlay Chemie].

11. Hostettmann, K., M. Hostettmann-Kaldas and K. Nakanishi: J. Chromatogr. 170, 355 (1979).

12. Hostettmann, K., M. Hostettmann-Kaldas and O. Sticher: Helv. Chim. Acta 62, 2079 (1979).

13. Kaldas, M., K. Hostettmann and A. Jacot-Guillarmod: Helv. Chim. Acta 57, 2557 (1974).

14. Hiller, K., M. Keipert and B. Linzer: Pharmazie 21,713 (1966).

15. Hiller, K. and G. Voigt: Pharmazie 32, 365 (1977).

16. Cheung, H. T. and M. C. Feng: J. Chem. Soc. C 1047, (1968).

17. Hostettmann, K.: Helv. Chim. Acta, 63, 606 (1980).

18. Hostettmann, K., M. Hostettmann-Kaldas and K. Nakanishi: Helv. Chim. Acta 61, 1990 (1978). 
19. Tanimura, T., H. Otsuka and Y. Ogihara: Kagaku no Ryoiki 29, 43 (1975).

20. Ogihara, Y., O. Inoue, H. Otsuka, K.-I. Kawai, T. Tanimura and S. Shibata: J. Chromatogr. 128, 218 (1976).

21. Tanaka, O. and S. Yahara: Phyrochemistry 17, 1353 (1978).

22. Yahara S., O. Tanaka and I. Nishioka: Chem. Pharm. Bull. 26, 3010 (1978).

23. Yahara, Y., K. Kaji and O. Tanaka: Chem. Pharm. Bull. 27, 88 (1979).

24. Otsuka, H., Y. Morita, Y. Ogihara and S. Shibata: Planta med. 32, 9 (1977).

25. Otsuka, H., S. Kobayashi and S. Shibata: Planta med. 33, 152 (1978).

26. Kimata, H., C. Hiyama, S. Yahara, O. Tanaka, O. Ishikawa and M. Airua: Chem. Pharm. Bull. 27, 1836 (1979).

27. Ishii, H., K. Tori, T. Tozyo and Y. Yoshimura: Chem. Pharm. Bull. 26, 674 (1978).

28. Hostettmann, $K$. and $M$. Hostettmann-Kaldas: unpublished results.

29. Abe, F. and T. Yamauchi: Chem. Pharm. Bull. 27, 1604 (1979).

30. Meier, B.: Thesis No. 6281, FTH Zürich 1978.

31. Hayashi, Y., T. Matsumoto, Y. Yuki and T. Sakan: Tetrahedron Lett. 4215 (1977).

32. Satake, T., T. Murakami, Y. Saiki and C.-M. Chen: Chem. Pharm. Bull. 262600 (1978).

33. Hostettmann-Kaldas, M. and K. Hostettmann: in preparation.

34. Numata, A., K. Hokimoto, A. Shimada, H. Yamaguchi and K. Takaishi: Chem. Pharm. Bull. 27, 602 (1979).

35. Tanaka, N., T. Murakami, Y. Saiki, C.-M. Chen and L. C. Gomez: Chem. Pharm. Bull. 26, 3580 (1978).

36. Suzuki, O., Y. Katsumata, M. Oya, V. M. Chari, R. Klapfenberger, H. Wagner and K. Hostettmann: Biochem. Pharmacol. 27, 2075 (1978).

37. Hostettmann, K.: unpublished results.

38. Brockmann, H. and W. Sanne: Chem. Ber. 90, 2480 (1957).
39. Inoue, K., Y. Shiobara, H. Nayeshiro, H. Inouye, G. Wilson and M. H. Zenk: J. C. S. Chem. Comm. 957 (1979).

40. Satake, T., T. Murakami, Y. Saiki and C.-M. Chen: Chem. Pharm. Bull. 26, 1619 (1978).

41. Tanaka, N., M. Kudo, T. Taniguchi, T. Murakami and Y. Saiki: Chem. Pharm. Bull. 26. 1339 (1978).

42. Orsuka, H., Y. Ogihara and S. Shibata: Phyrochemistry 13, 2016 (1974).

43. Hostettmann, K., M. Hostettmann-Kaldas and O. Sticher: J. Chromatogr. 186, 529 (1979).

44. Tani, C., N. Nagakura and N. Sugiyama: Ya kugaku Zasshi 95, 838 (1975).

45. Tani, C., N. Nagakura and S. Hattori: Yakugaku Zasshi 95, 1103 (1975).

46. Tani, C., N. Nagakura and C. Kuriyama: Yakugaku Zassh: 98, 1243 (1878); ibid.: 98, 1658 (1978).

47. Nagakura, N., G. Höfle, D. Coggiola and M. H. Zenk: Planta med. 34, 381 (1978).

48. Okamoto, K., H. Yonezawa and N. Izumiva: J. Chromatogr. 92, 147 (1974).

49. Nakayama, T., T. Nakajima and H. Sakabe: Proceedings of the 10th Symposium on Pepride Chemistry, J. Noguchi (Editor), Protein Research Foundation, Osaka, 1972, p. 176.

50. Takahashi, N., Y. Utsumi, T. Kato and N. Izumiya: J. Chromatogr. 109, 422 (1975).

51. Konobu, K.-J.. H. Takao and M. Kuroda: Y.akugaku Zasshi 96, 1379 (1976).

52. Kitagawa, 1., Y. Hamamoto and M. Kobavashi: Chem. Pharm. Bull. 27, 1934 (1979).

53. [to, Y. and R. L. Bowman: J. Chromatogr. Sci. 11, 284 (1973).

54. Sutherland, 1. A., G. H. Beaven and J. W. Lightbown: TIBS 1978, 133.

Address: Dr. K. Hostettmann, Pharmazeutisches Institut der ETH, ETH-Zentrum, CH-8092 Zürich, Siitzerland 